\title{
Sialylation is involved in cell fate decision during development, reprogramming and cancer progression
}

\author{
Fenjie $\mathrm{Li}^{1,2}$, Junjun Ding ${ }^{1,2 \bowtie}$ \\ ${ }^{1}$ Program in Stem Cell and Regenerative Medicine, The Third Affiliated Hospital of Sun Yat-Sen University, Zhongshan School \\ of Medicine, Sun Yat-Sen University, Guangzhou, China \\ ${ }^{2}$ Key Laboratory for Stem Cells and Tissue Engineering, Ministry of Education, Department of Cell Biology, Zhongshan School \\ of Medicine, Sun Yat-Sen University, Guangzhou, China \\ $\bowtie$ Correspondence: dingjunj@mail.sysu.edu.cn (J. Ding)
}

Received October 6, 2018 Accepted October 31, 2018

\begin{abstract}
Sialylation, or the covalent addition of sialic acid to the terminal end of glycoproteins, is a biologically important modification that is involved in embryonic development, neurodevelopment, reprogramming, oncogenesis and immune responses. In this review, we have given a comprehensive overview of the current literature on the involvement of sialylation in cell fate decision during development, reprogramming and cancer progression. Sialylation is essential for early embryonic development and the deletion of UDP-GICNAc 2-epimerase, a rate-limiting enzyme in sialic acid biosynthesis, is embryonically lethal. Furthermore, the sialyltransferase ST6GAL1 is required for somatic cell reprogramming, and its downregulation is associated with decreased reprogramming efficiency. In addition, sialylation levels and patterns are altered during cancer progression, indicating the potential of sialylated molecules as cancer biomarkers. Taken together, the current evidences demonstrate that sialylation is involved in crucial cell fate decision.
\end{abstract}

KEYWORDS sialylation, cell fate, development, reprogramming, cancer

\section{INTRODUCTION}

Sialylation refers to the terminal addition of sialic acid units to oligosaccharides and glycoproteins. Sialic acids belong to a family of nine-carbon backbone sugars and are typically found attached to the distal ends of glycans, which make them the "bridging" molecules between cells, as well as between cells and the extra-cellular matrix (Angata, et al., 2002; Chen and Varki, 2010). They were first isolated from submaxillary mucin by Gunnar Blix in 1936 (Blix, 1936), and were named "sialic acids" since they were acidic compounds derived from the saliva. In the early 1940s, Ernst Klenk isolated acidic glycosphingolipids comprising of sphingosine, fatty acid and hexoses, as well as neuraminic acids, which are abundant in the brain (Klenk, 1941). In 1957, Blix et al. found that neuraminic acids and the sialic acids isolated from saliva were the same, and modified the nomenclature accordingly (Blix, et al., 1957). And now, it has been found that sialic acids consist of $\mathrm{N}$-acetylneuraminic acid (Neu5Ac), N-glycolylneuraminic acid (Neu5Gc), deaminoneuraminic acid (Kdn), and their derivatives with modifications, such as methylation, acetylation and sulfation at the 4, 7, 8 and 9 positions, generating more than 50 sialic acid species (Angata and Varki, 2002) (Fig. 1A). Sialic acids are attached to both $\mathrm{O}$ - and $\mathrm{N}$-linked glycans (Fig. 1B) either at their galactose (Gal) or $\mathrm{N}$-acetylgalactosamine (GalNAc) units via $\alpha-2,3-$ or $\alpha-2,6$-bonds, or to other sialic acid moieties via $\alpha-2,8-$ or $\alpha-2,9-b o n d s$ (Table 1 ) by specific enzymes (Angata and Varki, 2002; Chen and Varki, 2010). Therefore, sialylated glycans show extensive structural diversity not only due to the number of monosaccharide units, but also the multiple linkages (Fig. 1B). This accords them a repertoire of biological functions in different processes including development, somatic cell reprogramming and cancer progression.

Approximately 200 types of cells have been identified in humans, based on morphological and functional characteristics (Bianconi, et al., 2013; Liang, et al., 2018). During embryonic development, various pluripotent and multipotent cells temporally and spatially express a series of lineage- 


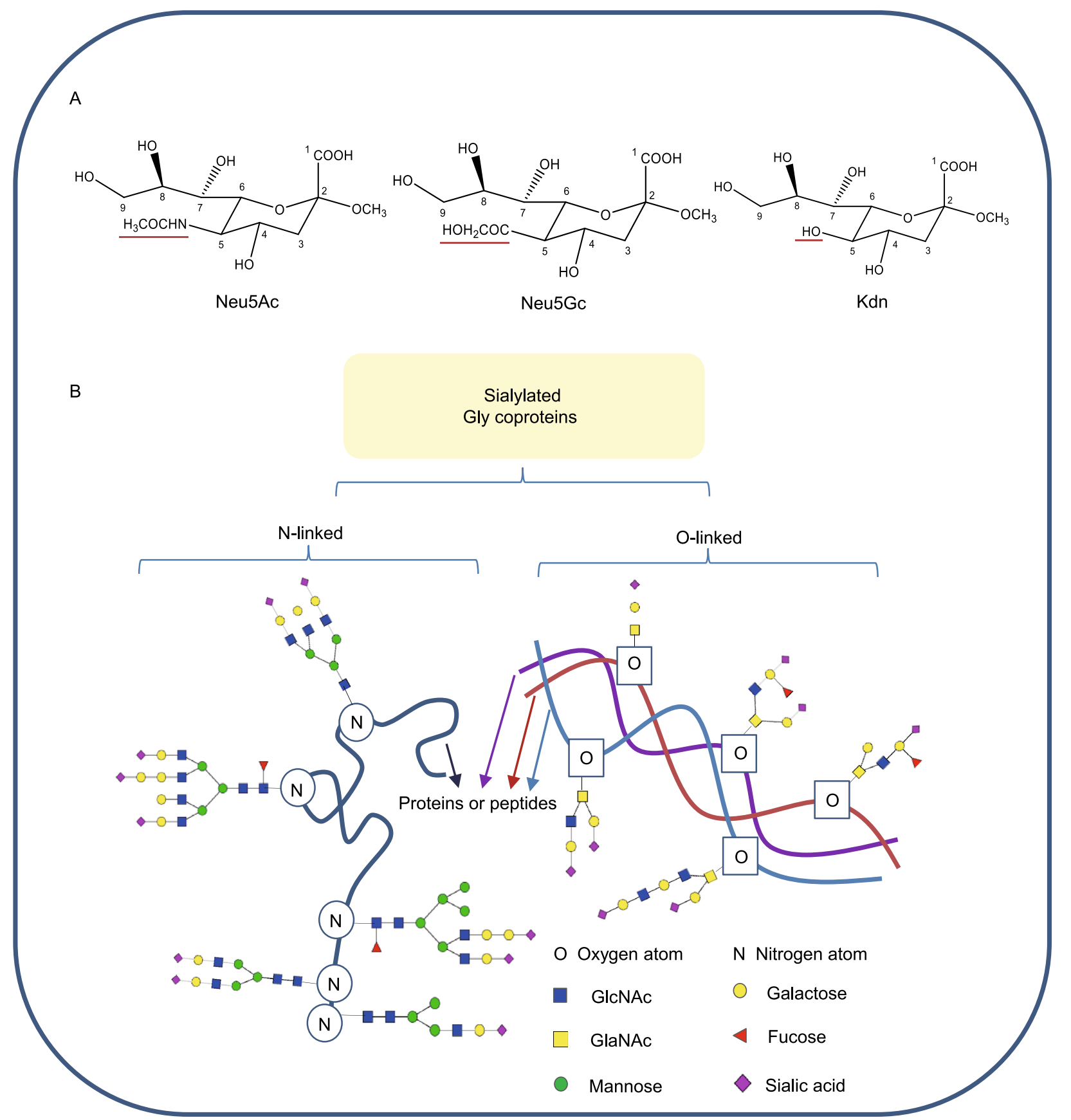

Figure 1. Structures of sialic acids and the diversity of sialylated glycoproteins. (A) Structures of sialic acids. Neu5Ac, Neu5Gc and $\mathrm{Kdn}$ are similarly structured and they possess different groups at the C5 position, which are red underlined. (B) The diversity of sialylated glycoproteins. Sialylated glycans can be attached to proteins or peptides through oxygen atom on serine/threonine or nitrogen atom on asparagine. And sialylated glycans can be linear or branched, comprised of multiple saccharides, including GlcNAc, GalNAc, mannose, fucose, galactose and so on.

specific genes, and differentiate into different mature cell types (Mincarelli, et al., 2018). These terminally-differentiated somatic cells are generally stable and maintain a homeostasis between proliferation and quiescence. And if ever, cells switch from one state to another would lead to diseases, including cancers (Zhou and Melton, 2008).
Somatic cells, however, can be reprogrammed to a different cellular state by manipulating the expression of specific transcription factors or by exposing them to defined small molecules. Takahashi and Yamanaka were the first to generate pluripotent cells from adult somatic cells using the four transcription factors Oct4, Sox2, c-Myc and Klf4 (Takahashi 
Table 1. The major patterns of sialylated glycoconjugates. $\square$ GIcNAc, $\bigcirc$ Galactose, $\varangle$ Fucose, $\diamond$ Sialic acid.

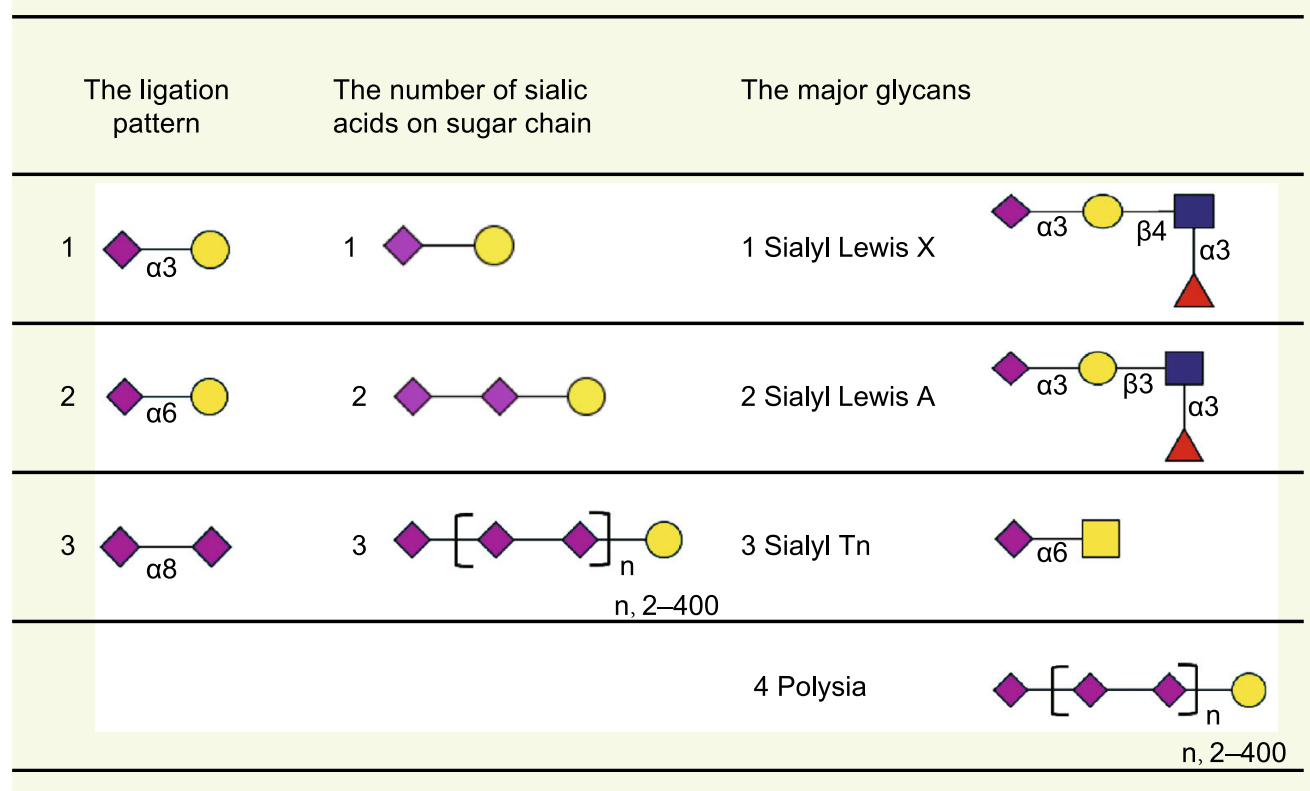

and Yamanaka, 2006). Their pioneering "induced pluripotent stem cell" (iPSC) technology is an ethically acceptable and robust method to convert differentiated cells to pluripotent cells, which can then be directed to produce specific cell types using the requisite factors, for tissue repair and therapy. The mechanisms underlying cell fate decision have been extensively explored, including DNA methylation, histone modifications, RNA editing, gene silencing and so on (Bonasio, et al., 2010; Moris, et al., 2016). The regulating factors include transcription factors, chromatin remodelers and so many other proteins, which are tightly controlled by post-translational modifications (PTMs), such as acetylation, methylation, phosphorylation and glycosylation (Wang, et al., 2014). Protein function can be diversified and extended by PTMs beyond what is dictated by gene transcripts, allowing cells to dynamically regulate their signal integration and physiological states (Chu, et al., 2014; Yang and Qian, 2017). Sialylation, as one of the important PTMs, has been reported to be involved in cell fate decision in emerging data.

In this review, we have given a comprehensive overview of the current literature on sialylation and its role in cell fate decisions during development, reprogramming and cancer progression, in order to provide new insights about the mechanisms in somatic cell reprogramming, cell lineage specification during development and how cells convert to cancer cells.

\section{THE BIOSYNTHESIS PATHWAY OF SIALYLATION}

The mammalian biosynthetic pathways of sialic acids and sialylated glycans have been unraveled in the past couple of decades (Fig. 2), and more than twenty enzymes (Comb and
Roseman, 1958; Ghosh and Roseman, 1961; Roseman, et al., 1961; Jourdian, et al., 1964; Coates, et al., 1980; Hamamoto, et al., 1993; Sasaki, et al., 1993; Lee, et al., 1994; Yoshida, et al., 1995; Kurosawa, et al., 1996; Eckhardt and Gerardy-Schahn, 1998; Kono, et al., 1998; Ikehara, et al., 1999; Okajima, et al., 1999, 2000; Takashima, et al., 1999, 2002; Krzewinski-Recchi, et al., 2003) (Table 2), including the Golgi-localized sialyltransferases have been identified. Neu5Ac, the best characterized sialic acid in humans, is synthesized from UDP-N-acetyl-glucosamine (UDP-GIcNAc), which in turn is produced by the hexosamine pathway in the cytosol (Fig. 2) (Hanover, 2001). UDPGlcNAc (Lau, et al., 2007) is first converted to N-acetyl-Dmannosamine (ManNAc), the first precursor of sialic acid, by the rate limiting UDP-N-acetylglucosamine-2-epimerase/Nacetylmannosamine kinase (UDP-GlcNAc 2-epimerase), which also converts ManNAc to N-acyl-D-mannosamine 6-phosphate (ManNAc-6P). The latter is converted to $\mathrm{N}$-acylneuraminate 9-phosphate (Neu5Ac-9P) by $\mathrm{N}$-acetylneuraminate-9-phosphate synthase. In the final cytosolic step, N-acylneuraminate-9-phosphatase converts Neu5Ac9P to Neu5Ac, which then enters the nucleus and is converted to cytidine $5^{\prime}$-monophosphate $\mathrm{N}$-acetylneuraminic acid (CMP-Neu5Ac) by CMP-NeuNAc synthase. In most non-human species, however, a proportion of CMP-Neu5Ac is converted to cytidine 5'-monophosphate N-glycolylneuraminic acid (CMP-Neu5Gc) by CMP-Neu5Ac hydroxylase. These nucleotide sugars are transported into the Golgi apparatus where a myriad of sialyltransferases (up to 20 celland tissue-dependent in humans) generate $\alpha-2,3-, \alpha-2,6-$, or $\alpha-2,8-l i n k e d$ sialo-glycoconjugates. Finally, the sialo-glycoproteins or gangliosides are hydrolyzed by neuraminidases, 
Figure 2. The biosynthesis pathway of sialylation. The nucleotide sugar UDPGICNAc, the production of hexosamine pathway, is converted into ManNAc by UDP-GIcNAc 2-epimerase (whose encoding gene is GNE in human). ManNAc is metabolic precursor for the synthesis of sialic acid and produces Neu5Ac in the cytosol, which then enters the nucleus to produce CMPNeu5Ac. CMP-Neu5Ac are transported into Golgi where they are used by ST3GAL16, ST6GAL1-2/ST6GALNAC1-6, ST8SIA4 to produce $\alpha-2,3-, \alpha-2,6-$ and $\alpha-$ 2,8-linked sialoglycoproteins or gangliosides, respectively. Finally, sialosides are recycled by neuraminidases, regenerating sialic acid monomers that can be reused.

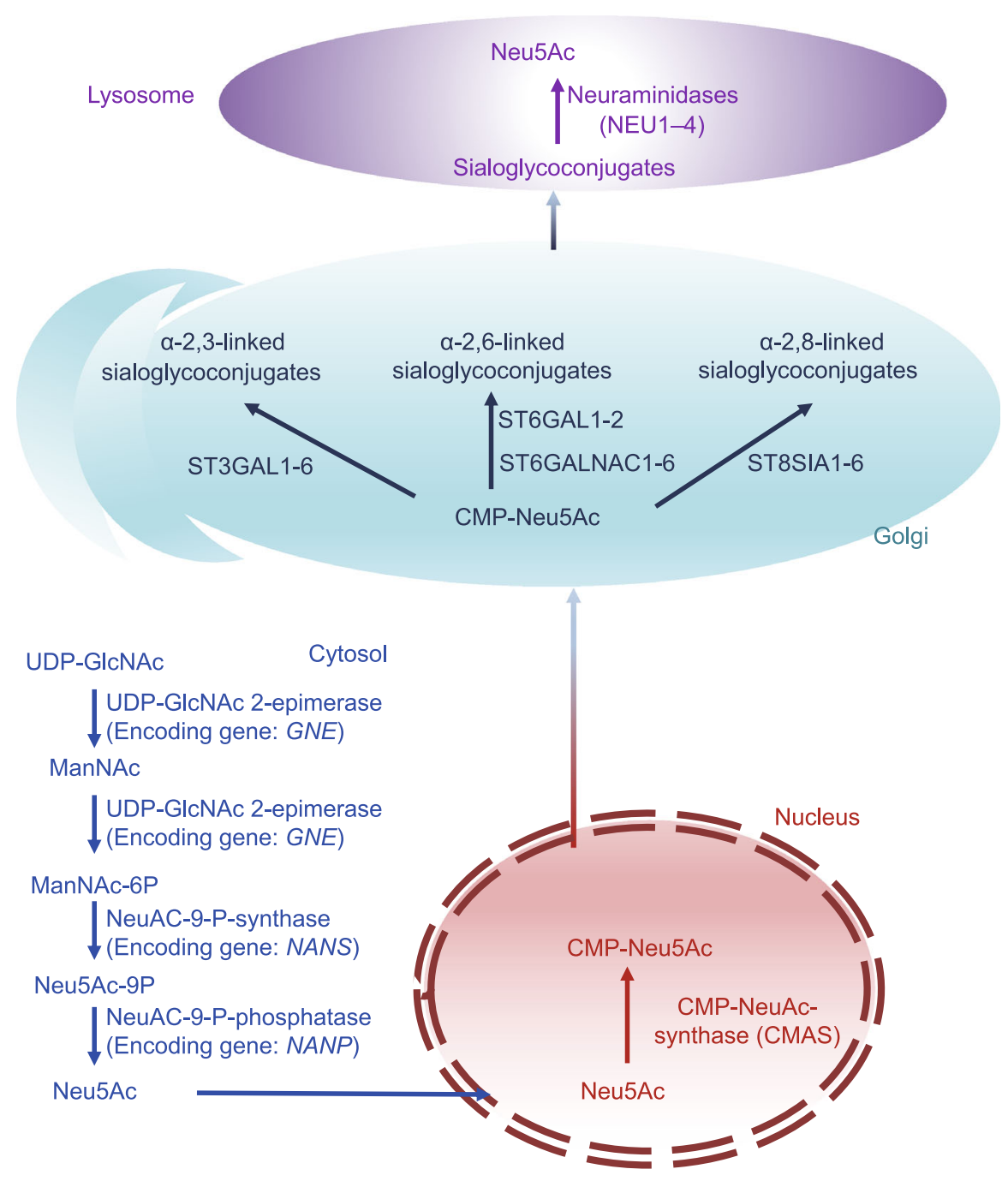

which regenerate sialic acids that can be salvaged to synthesize more sialo-glycoconjugates (Du, et al., 2009).

\section{THE IMPACT OF SIALIC ACID ON CELL ADHESION AND SIGNALING}

Since sialic acid is negatively charged, it is considered an anti-adhesive glycotope, whereas, negatively charged sialic acid can also act as receptor for specific ligands, including Siglecs and selectins, delivering signals between cells.
The negative charge of sialic acid significantly contributes to the biophysical properties of sialylated cells. For example, erythrocytes are heavily sialylated and therefore negatively charged (Varki, 2008), as is the luminal surface of the vascular endothelium which is also densely covered with sialic acid residues (Born and Palinski, 1985). This results in mutual charge repulsion between the two which prevents the erythrocytes from attaching to the vascular endothelium and allows them to circulate freely (Fig. 3). Weber and coworkers reported that the sialylation of endothelial ICAM-2 and platelet ICAM-2 was different and it contributed to the different 


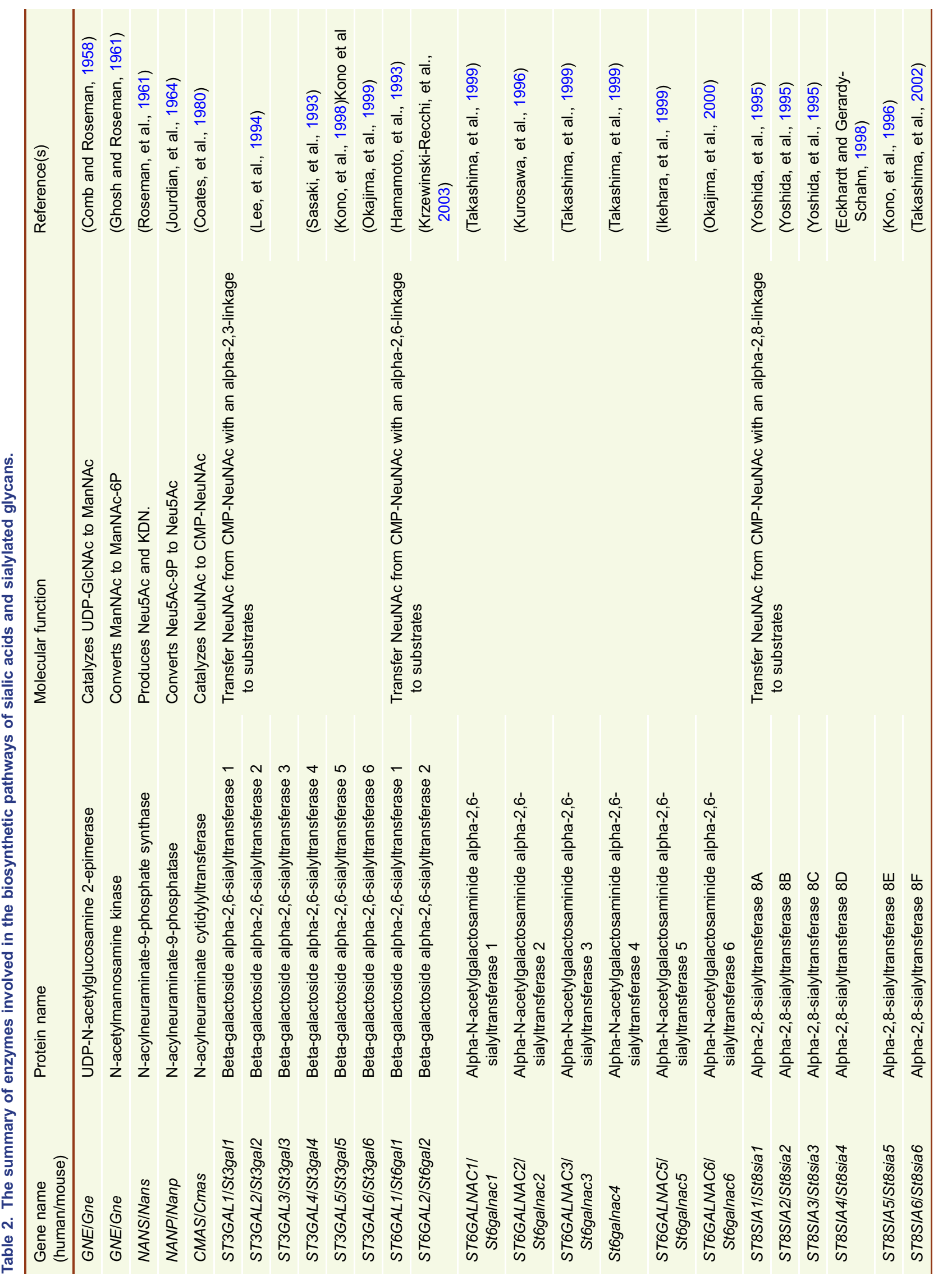


A

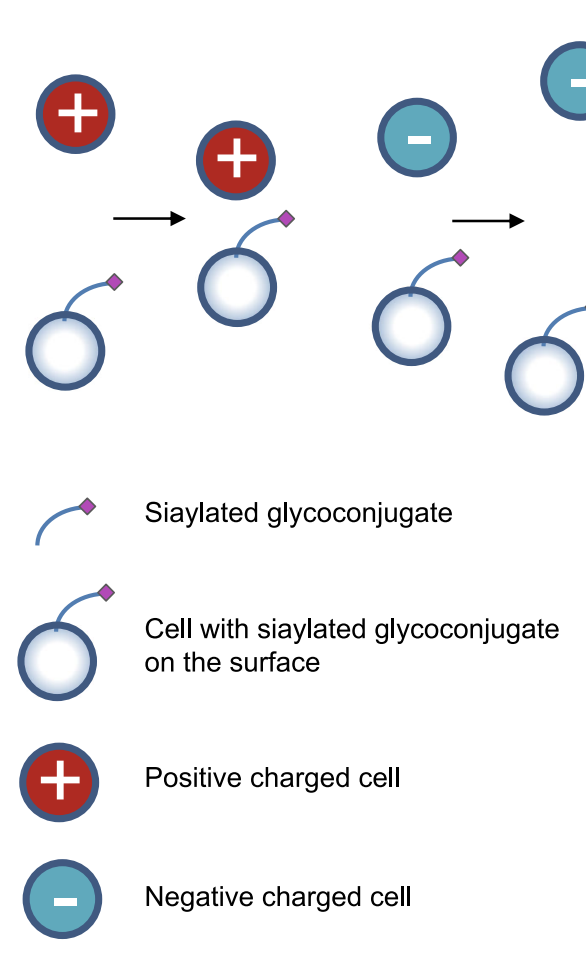

B

Figure 3. Sialic acid that on cell surface provides charge adhesion to positive cells (A) and charge repulsion to negative cells (B).

adhesion behaviors of endothelial and platelet. Endothelial ICAM-2 supported $50 \%$ more adhesion of T cells than did platelet endothelial cell ICAM-2. And these functional differences was destroyed by treatment of platelet ICAM-2 with neuraminidase, thus it was due to cell-specific sialylation (Weber, et al., 2004). These collectively demonstrated that negatively charged sialic acid served as an anti-adhesive glycotope and prevent cell adhesion.

In addition, both intracellular and surface sialylated glycans are involved in signal transduction, since the sialic acid residues also act as receptors for specific ligands, including Siglecs and selectins. Sialic acid moieties not only relay signals between cells, but also deliver external stimuli to the inside of the cell and vice-versa. The roles of sialylation in signal transduction will be discussed in more details in the following sections.

\section{ROLES OF SIALYLATION IN CELL FATE DECISION}

Sialylation regulates development

The role of sialylation during early embryonic development

The role of sialylation in early embryonic development was first explored in 2002. Heterozygous mice lacking one allele of the UDP-GIcNAc 2-epimerase encoding gene Gne showed no abnormalities, but did not give rise to any homozygous knockouts (with no change in the Mendelian probability of the wild-type littermates), indicating early embryonic lethality of Gne inactivation (Schwarzkopf, et al., 2002). Furthermore, genotyping the embryos at E8.5, E9.5 and E10.5 revealed $10 \%, 6 \%$ and $0 \% \mathrm{Gne}^{-/-}$embryos respectively, indicating that the inactivation of UDP-GIcNAc 2-epimerase is lethal before E10.5. Early stage embryos include a population of pluripotent cells known as embryonic stem cells (ESCs) that can be expanded in vitro (Evans and Kaufman, 1981; Zhao, et al., 2015). Since Schwarzkopf et al. also demonstrated that sialylation is required for stem cell maintenance (Which will be discussed further below in next text), it is reasonable to postulate that impaired sialylation in the early embryonic stages may disturb the normal state of the pluripotent cells in early stage embryo and impede their differentiation, consequently resulting in aberrant embryonic development. The early lethality of Gne deficiency may also be due to disruption in cell-cell adhesion and cell migration. During development, adhesion between cells activates the signaling pathways essential for survival, migration and differentiation (Kashef and Franz, 2015). Melo-Braga et al. reported that numerous cell adhesion molecules involved in early embryonic development are sialylated glycoproteins such as E-cadherin, integrin and catenin (Melo-Braga, et al., 2014). Aberrant sialylation could inhibit the interaction between these adhesion molecules and their receptors, thereby blocking signal transduction associated with the developmental process.

Abeln et al., however, found that Cmas-mediated sialylation was dispensable for early murine embryonic development in vitro (Abeln, et al., 2017). The nuclear-located CMP-Sia synthase, whose encoding gene is Cmas, converts Neu5Ac to its cytidine-monophosphate diester (Fig. 3). They generated Cmas deficient murine ESCs and found that CMAS was the only enzyme producing activated sialic acid as the donor sugar for sialytransferases, and deletion of Cmas led to the complete loss of cell surface sialylation. They analyzed the mRNA expression pattern of two undifferentiated WT and three $\mathrm{Cmas}^{-1-} \mathrm{mESC}$ s and resultant EBs after 2, 4 and 8 days of differentiation. They subjected the data to PCA analysis and concluded that the data points were still close together. However, the data points at day 8 of differentiation were not as close as they were at day 0,2 and 4. Maybe a long time-course study should be carried out to achieve a more definite conclusion. Additionally, they found the mRNA expression patterns of endo-, ecto- and mesoderm-specific genes unimpaired in $\mathrm{Cmas}^{-1-} \mathrm{EBs}$, however, the performance of RNA-seq may be appreciated to compare the diversity of gene expression comprehensively.

Obviously, further studies are needed to determine the importance of sialylation in development.

\section{Sialylation regulates neurodevelopment}

Sialic acid, unlike other sugars, can often form homo-oligo/ polymers like disialic acid (diSia), oligosialic acid (oligoSia) and polysialic acid (polySia) (Sato and Kitajima, 2013). So 
far, only several glycoproteins are found to be polysialylated, maybe polysialylation is protein specific and restricted in limited substrates, including the neural cell adhesion molecule (NCAM), the synaptic cell adhesion molecule (SynCAM1), neuropilin-2 (NRP-2), the $C-C$ chemokine receptor type 7 (CCR7), E-selectin ligand-1, the a subunit of the voltagedependent sodium channel, CD36 scavenger receptor in human milk, and the polysialyltransferases themselves, which are capable of autopolysialylation (James and Agnew, 1987; Close and Colley, 1998; Yabe, et al., 2003; Muhlenhoff, et al., 2013; Kiermaier, et al., 2016; Werneburg, et al., 2016).

Polysialylation is associated with the plasticity of the nervous system, and sialic acids are more abundant in the neuronal cell membranes compared to other tissues (Svennerholm, et al., 1989). The major membrane protein polysialylated in mammalian cells is NCAM (Wang, 2012). Polysialic acid is a linear homopolymer of negatively charged Neu5Ac residues, and can imbibe considerable amounts of water, resulting in increased size and volume. Therefore, presence of polysialic acid chains on cell surfaces restricts both homophilic and heterophilic binding due to negative charge repulsion and inter-cellular steric hindrance respectively (Yang P, 1994). Due to these properties, polysialic acid is considered an anti-adhesive glycotope impacting cell adhesion and signaling. In addition, polysialic acid specifically binds to neurotrophins, growth factors and neurotransmitters in a chain length-dependent manner (Sato and Kitajima, 2013). The complexes formed by polysialic acid with different neurotrophic factors are involved in synaptic plasticity and neurogenesis. Consistent with this, polysialicNCAM has been shown to be a key neuroplastic molecule pivotal for memory formation, and decreased polysialic acid is a major factor in the development of schizophrenic brains (Kochlamazashvili, et al., 2010).

The distribution of sialic acids in different regions of the brain is highly dynamic and undergoes changes during development. For example, polysialic acids account for $30 \%$ of the molecular mass of NCAM in newborn rats and decrease to $10 \%-14 \%$ at $6-8$ days after birth, and then to only $4 \%$ in 28-day-old rats (Margolis and Margolis, 1983). In addition, the activity of UDP-GICNAc 2-epimerase is lower in rat pups compared to the adults (Gal, et al., 1997). Similarly, human infants may not have the full capacity to endogenously synthesize the requisite amounts of sialic acids (Dickson and Messer, 1978), and rely on exogenous sources to supply enough sialic acids for the rapidly growing brain. Consistent with this hypothesis, sialic acid concentration is abundant during early milk production and decreases as the lactation period progresses (Wang, et al., 2001). Furthermore, the brain sialic acid concentration was found to be significantly higher in breast-fed infants compared to the formula-fed infants, and correlated to the docosahexaenoic acid (DHA) present in breast milk (Wang, et al., 2003). This indicates that sialic acid and DHA act synergistically during early neurodevelopment and cognition. Taken together, the higher levels of sialylation in the breast-fed infants' brains could be the underlying cause of the better neurological and intellectual performance seen in breast-fed compared to formula-fed infants (Wang, et al., 2003; Wang, 2009, 2012). In agreement with this, a dose-dependent relationship has been observed between dietary sialic acid supplementation and cognitive function (Wang, et al., 2003; Wang, 2012)

Karnebeek et al. reported that $\mathrm{N}$-acetylneuraminate-9phosphate synthase, one of the enzymes involved in sialylation, is also essential for brain and skeletal development (van Karnebeek, et al., 2017). Bi-allelic mutations in NANS, the gene encoding for this enzyme, was identified in individuals with infantile-onset severe developmental delay and skeletal dysplasia. In addition, N-acetyl-D-mannosamine levels were elevated in their body fluids, and enzyme activity was significantly reduced in the patient-derived fibroblasts, which inhibited incorporation of sialic acid precursors into glycoproteins. In addition, nansa (the counterpart of NANS in zebrafish) knockdown in zebrafish embryos led to aberrant skeletal development, which could be partially rescued by adding sialic acid exogenously.

Clearly, further studies are needed to elucidate the molecular mechanisms underlying the role of sialylation on neurodevelopment and that of dietary sialic acid on cognitive function, in order to consider sialic acid as a potential therapeutic agent in neurological disorders.

\section{Sialylation is pivotal for somatic cell reprogramming and maintaining stem cell pluripotency}

The ability to self-renew indefinitely and differentiate into all cells of the body makes pluripotent stem cells, including embryonic stem cells (ESCs) and induced pluripotent stem cells (iPSCs), valuable for research and clinical applications that require specific cell types (Wang, et al., 2014). Although recent studies have greatly advanced our understanding of cellular pluripotency and its potential utility, it is still not completely understood how these cells establish, maintain and modulate their pluripotency during cellular reprogramming (Zhao, et al., 2018). Recently, several independent studies demonstrated that the sialylation is essential for the establishment and maintenance of stem cell pluripotency. Wang et al. reported a significant change in protein sialylation levels during differentiation, with higher levels of the ST6GAL1 sialyltransferase in the undifferentiated human PSCs compared to the non-pluripotent cells. Furthermore, knockdown of the St6Gal1 gene, as well as presence of a sialyltransferase inhibitor decreased the efficiency of somatic cell reprograming (Wang, et al., 2015). In addition, proteins extracted from human PSCs showed stronger binding to the Sambucus nigra lectin (SNA), which specifically recognizes $\alpha-2,6$ sialylated galactosides. ST6GAL1 inhibition in human PSCs also downregulated OCT4 protein levels and altered the expression of several genes involved in cell morphogenesis during differentiation. 
Changes in cell surface sialylation have recently been implicated in mediating epithelial-mesenchymal transition (EMT). EMT and mesenchymal-epithelial transition (MET) are two fundamental processes involved in embryonic development, organ formation and pluripotency regulation. During the establishment of pluripotency, MET is initiated and is required for the nuclear reprogramming of mouse fibroblasts (Li, et al., 2010). Recently, Liu et al. showed that the sequential delivery of Oct4, KIf4, c-Myc and Sox2 initiated an EMT-MET process that resulted in more efficient reprogramming of the cells, compared to when the factors were delivered simultaneously, suggesting that switching between the mesenchymal and epithelial fates is the basis of reprogramming (Liu, et al., 2013). Jun Du discovered that sialylation was down-regulated during EMT, as were the expression levels of genes involved in sialic acid biosynthesis (Du, et al., 2015). They identified a set of dynamically regulated sialylated proteins during EMT using quantitative proteomic analysis, of which integrin $\beta 4$, a cell surface adhesion receptor, showed significant downregulation in its sialylation levels during EMT. These collectively suggest that sialylation-mediated EMT regulate somatic cell reprogramming.

Distinct alterations in sialylation also accompany the loss of pluripotency in human PSCs (Hasehira, et al., 2012). A quantitative glycome analysis of undifferentiated human iPSCs and differentiated human dermal fibroblasts showed a change from the $\alpha-2,3$ to the $\alpha-2,6$ bond in the sialic acids on $\mathrm{N}$-linked glycans during differentiation. The expression profiles of relevant sialyltransferase genes were fully consistent with these results. Saito et al. also found that human iPSCs had unique sialylated glycans and glycoforms compared to somatic cells, indicating a regulatory role of protein sialylation in cellular pluripotency (Saito, et al., 2011). They analyzed the RNA and glycan profiles of various human somatic cells and iPSC lines, and identified sialylated glycan signatures associated with differentiation, suggesting that protein sialylation may be important for the control of cell differentiation and pluripotency maintenance.

Collectively, these evidences demonstrated that sialylation is required for somatic cell reprogramming and stem cell pluripotency maintenance. However, more studies should be carried out to investigate the underlying molecular mechanisms.

\section{Sialylation is involved in malignant transformation}

Sialic acid has pKa of 2.6 and thus imparts a negative charge to the cell-surface glycoproteins at physiological $\mathrm{pH}$ (Eylar, et al., 1962), which can affect their conformation and oligomerization, as well as their interactions with other cellular and extra-cellular matrix proteins. Furthermore, sialylated glycans are the ligands of numerous proteins that control crucial biological processes (Deng, et al., 2013; Gerardy-Schahn, et al., 2015), including malignant transformation. The transformation of normal cells to heterogeneous cancer cells is accompanied by an aberrant transcriptome and proteome (Liang, et al., 2018), and as some studies indicate, by aberrant sialylation patterns as well. Therefore, the altered sialylated moieties on cancer cells can serve as potential biomarkers to distinguish them from the healthy cells. These sialylated biomarkers include total sialic acids, sialylated glycoproteins and carbohydrate antigens.

\section{Sialylated molecules are potential cancer biomarkers}

Total sialic acid Sialic acids were first recognized as specific tumor markers and potential therapeutic targets in the 1960s following the discovery of higher total sialic acids (TSA) content on the surface of cancer cells (Macbeth R A L, 1962). TSA includes the glycoproteins, glycolipid bound sialic acids, as well as free sialic acids. Serum TSA, normalized sialic acids levels such as TSA/total protein (TP) or bound sialic acids/TP have also been subsequently recognized as potential markers for cancer diagnosis, staging or prognosis, as they are upregulated in different cancers (Shah, et al., 2008; Sawhney and Kumar, 2011). However, despite extensive research on their potential as onco-therapeutic targets, the results had not been encouraging.

Sialylated glycoproteins as cancer biomarkers The advancement of mass spectrometry remarkably accelerated the characterization of sialic acids and cancer specific sialylated glycoproteins. The current hypothesis is that the sialylation pattern of a cell is altered during malignant transformation, which is reflected in the spectrum of sialylated glycoproteins secreted by the tumor cells (Pinho and Reis, 2015). Several sialylated glycoproteins have in fact been approved as cancer biomarkers by Food and Drug Administration (FDA), including prostate-specific antigen (PSA) and thyroglobulin (Table 3) (Ludwig and Weinstein, 2005; Badr, et al., 2014). In prostate cancer, it was convinced that PSA can indicate some cases of prostate cancer, however, it displayed some limitations in early detection. Schroeder, et al. reported that PSA-based screening of prostate cancer reduced the rate of death by $20 \%$ but was associated with a high risk of overdiagnosis (Schroeder, et al., 2009). There is also convincing evidence that a substantial portion of men who have prostate cancer detected by PSA screening have a tumor that will progress so slowly or

Table 3. The list of sialylated glycoproteins as cancer biomarkers approved by FDA.

\begin{tabular}{lll}
\hline Biomarker & Cancer type & Clinical use \\
\hline a-fetoprotein & Liver & Monitoring \\
CA 125 & Ovarian & Monitoring \\
Thyroglobulin & Thyroid & Monitoring \\
PSA & Prostate & Monitoring \\
Mucin & Bladder & Monitoring \\
\hline
\end{tabular}


Table 4. Sialylated glycoforms of IgG (Pucic, et al., 2011).

\begin{tabular}{ccc}
\hline GP16 GP17 & GP18 \\
\hline GP21 GP22 & GP23 & GP24 \\
\hline & 0 & GP19 \\
\hline
\end{tabular}

even not progress that it would have remained asymptomatic for the man's lifetime (Moyer and Force, 2012). Recently, PSA specific glycosylation changes have been characterized by mass spectrometry analysis and the levels of $\alpha-2,3-$ linked sialic acids on PSA was significantly different in cancer patients compared to controls, indicating that sialylation of PSA has great potential in discriminating cancer patients from controls, thereby improving prostate cancer diagnosis (Tajiri, et al., 2008; Yoneyama, et al., 2014; Pihikova, et al., 2016). Maybe it is the $\alpha-2,3$-linked sialylated PSA but not $P S A$ in all forms that is associated with prostate cancer.

The serum levels of immunoglobulin $G(\mathrm{IgG})$ sialylated glycoforms (Table 4) and alterations in IgG sialylation are also associated with cancer and other diseases (Parekh, et al., 1985; Kodar, et al., 2012). Decreased IgG sialylation has been observed in various cancers, including colorectal cancer (Theodoratou, et al., 2016; Vuckovic, et al., 2016), gastric cancer (Kodar, et al., 2012; Zhang, et al., 2016) and ovarian cancer (Saldova, et al., 2008). However, IgG sialylation is increased in myelomas (Fleming, et al., 1998), indicating that cancer-associated changes in IgG sialylation depends on the cancer type.

Changes in mucin sialylation lead to decreased mucosal protection, loss of cell-contact inhibition and aberrant interaction with bacterial populations. The modified mucin ligands on the ensuing cancer cells have aberrant receptor binding function, which increases their proliferation, invasion and metastasis. Increased mucin sialylation is associated with breast cancer (Cazet, et al., 2010), and is correlated to higher levels of sialyltransferase ST3GAL1 (Dalziel, et al., 2001). In gastric cancer, changed sialylation pattern of mucin, including Sialyl Lewis A (CA19-9) and Sialyl Lewis X (SLX) (Table 1), has been identified (Santos-Silva, et al., 2005) and CA19-9 may be potential prognostic marker (Baldus, et al., 1998). As in gastric cancer, the expression of mucin SLX is also enhanced in colorectal cancer and sialateO-acetyltransferase (OAT), which acetylates sialic acids, has been found to be deleted in colorectal cancer, leading to the development of cancer (Corfield, et al., 1999). For detailed information, please see reviews by Corfield (Corfield, 2015).
With the advancement of mass spectrometry, a panel of sialylated glycoproteins could be identified simultaneously, accelerating the screening of cancer markers. For example, Zhao et al. identified approximately 130 sialylated glycoproteins and found sialylated plasma protease $\mathrm{C} 1$ inhibitor was down-regulated in pancreatic cancer serum (Zhao, et al., 2006).

Nevertheless, though the results mentioned above showed great potential for sialylation changes on specific glycoproteins, only a few of them were validated and there is still a long way to go for the translation of these markers from the laboratory to the clinics.

Carbohydrate antigens as cancer biomarkers Carbohydrate antigens are glyco-conjugates widely expressed on cell membranes and can be detected by specific monoclonal antibodies. Many carbohydrate antigens are associated with metastasis in several carcinomas, and affect patient survival (Hakomori, 1985). The most common tumor-associated carbohydrate antigens are CA19-9, SLX and SialyI Tn (STn) antigens (Table 1), all of which are sialylated glycans (Duraker, et al., 2007; Kannagi, 2007). High serum levels of CA19-9, SLX and STn have been correlated to liver metastasis in gastric cancer. Furthermore, increased levels of CA19-9 in the serum is a predictor of poor prognosis of colorectal cancer after surgery (Jiang, et al., 2017). In addition, serum CA19-9 has now been used as biomarker in pancreatic cancer (Ballehaninna and Chamberlain, 2012) and it also displayed great potential for metastasis in colorectal cancer (Stojkovic Lalosevic, et al., 2017). STn is a potential marker for early detection of colon carcinogenesis, as well as predictive of distant metastasis and mucinous carcinoma in colorectal cancer (Nakagoe, et al., 2001).

\section{Sialyltransferases and neuraminidases are associated with cancer}

Aberrant sialylation levels and patterns associated with cancer indicate the involvement of sialylation enzymes in oncogenesis. Abnormal levels of several glycosyltransferases 
have been observed in various human cancers (Henderson and Kessel, 1977; Suzuki, et al., 2015; Cui, et al., 2016). Higher levels and activity of total serum sialyltransferases are associated with advanced breast cancer stage, indicating that sialyltransferases are associated in evaluating cancer progression (Dao, et al., 1980).

The sialyltransferase ST6GAL1 has been reported to be upregulated in various cancers, contributing to increase tumor aggressiveness, metastasis and enhance cancer cells' resistance to chemotherapy. Several studies have illustrated that oncogenic Ras activation can lead to upregulation of ST6GAL1, which caused altered sialylation of beta 1 integrin and consequently its adhesion to collagen I changed (Le Marer, et al., 1992; Seales, et al., 2003, 2005). It has been recently shown that $\alpha-2,6$-sialylation of FasR inhibits binding of Fas-associated adaptor molecule (FADD) to the FasR death domain, impairing the formation of the death-inducing signaling complex (DISC) and blocking apoptotic signaling (Swindall and Bellis, 2011) (Fig. 4). Additionally, ST6GAL1 was reported to protect tumor cells against hypoxia by enhancing HIF-1 $\alpha$ signaling. Cells grown in hypoxia showed increased ST6GAL1 expression, and the HIF-1a mRNA was increased in ST6GAL1-enriched cells, suggesting that ST6GAL1 may enhance HIF-1 $\alpha$ expression (Jones, et al., 2018). These collective evidences indicate that sialylation serves as a molecular switch to divert signaling toward tumor cell survival.

Sialyltransferases can also regulate cancer cell progression through interacting with transcription network. Matthew J. Schult and colleagues demonstrated that ST6GAL1 is upregulated in ovarian and pancreatic carcinomas and induced expression of Sox9 and Slug, the key tumor-promoting transcription factors (Schultz, et al., 2016). In addition, the proto-oncogene $c-M y c$, has been reported to regulate transcription of the sialyltransferases ST3GAL1, 2 and 5, resulting in increased expression of SLX/CA19-9 antigens and facilitated tumor cell motility (Sakuma, et al., 2012) (Fig. 4). Interestingly, it was demonstrated that in hormone-sensitive prostate cancer cells, androgens control ST3GAL2 transcription by inducing promoter demethylation, increasing GD1a expression, a sialoganglioside associated with tumor progression (Hatano, et al., 2012).

Neuraminidases (NEU), also known as sialidases, cleave sialic acid residues from glycol-conjugates and are associated with cancer progression (Miyagi, et al., 2012). Four mammalian NEU homologues are known so far-NEU1, NEU2, NEU3 and NEU4-of which NEU 1, 2 and 4 are downregulated in various cancers, resulting in sialoglycan accumulation in cancer cells. In contrast, NEU3 is significantly up-regulated in many human cancers (Kakugawa, et al., 2002; Nomura, et al., 2006; Hata, et al., 2015). Raval et al. found that sialyltransferase activity, and the levels of sialic acids and sialylated glycoproteins were upregulated in breast cancer and oral carcinoma cells, and decreased upon anticancer treatment (Raval, et al., 2003). Taken together, sialylated glyco-antigens are promising potential cancer

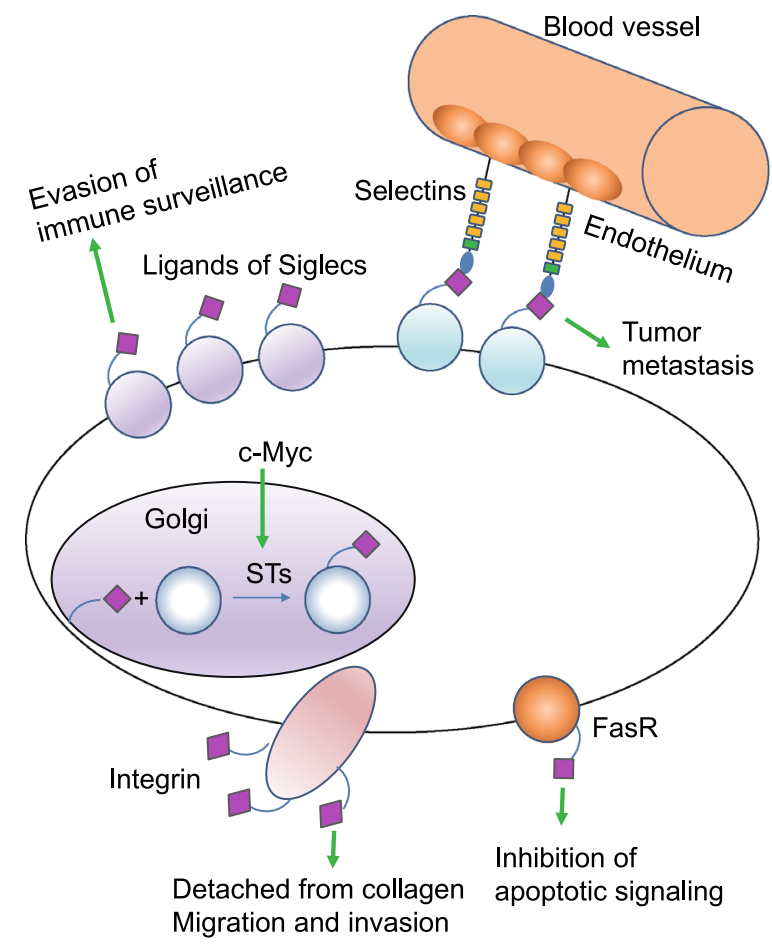

Figure 4. Sialylation is found to be aberrant in cancers compared to healthy controls, facilitating tumor growth and progression. In cancer cells, the proto-oncogene $c$ $M y c$, increase the expression of sialyltransferases (STs) in cancer cells. Therefore, the synthesis of sialylated glycans in the Golgi system by STs is enhanced. The aberrant high expression of sialylated glycans on Fas receptor (FasR) impairs the interaction between FasR and Fas, inhibiting apoptotic signaling transduction and preventing cancer cells from death. Moreover, increased sialylation on integrins can induce detachment from collagen, promoting cancer cell migration and tissue invasion. Cancer cell surfaces are enriched with glycans capped with SLX oligosaccharides which can interact with selectins, promoting cancer cells to adhere to and extravasate through the endothelium. Siglecs regulate immune surveillance of cancer and aberrant sialylation leads to Siglecs deficiency in cancer cells, preventing cancer cells from attack by immune system.

biomarkers, considering sialyltransferases and neuraminidases are associated with cancers, therefore more studies are needed to be validated for pre-operative diagnosis.

\section{Sialylation-mediated immunity regulates cancer progression}

Selectins, a family of single-chain transmembrane glycoprotein cell adhesion molecules (CAM), bind to SLX (Table 1) oligosaccharides, and are responsible for cell tethering and rolling on the vascular endothelium. This specific lectin-ligand system mediates the subsequent transmigration of 


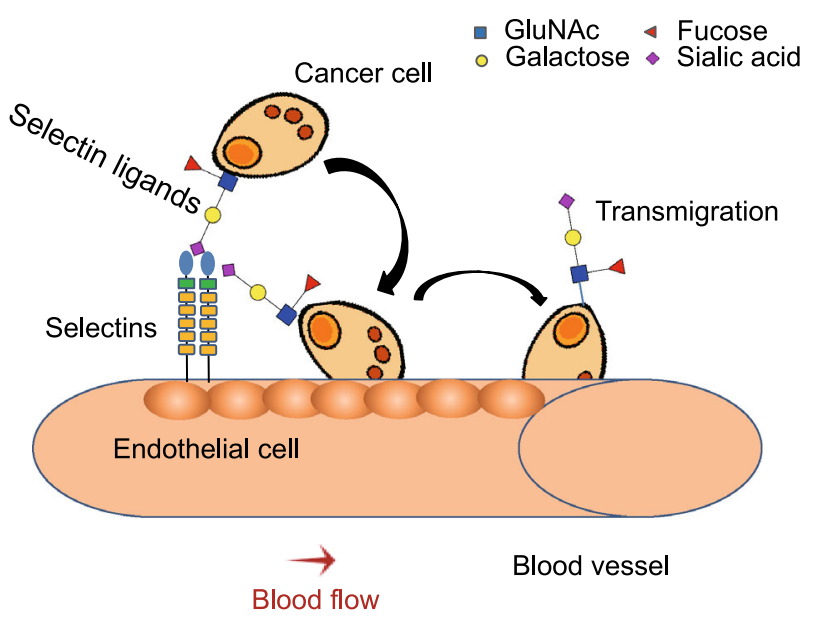

Figure 5. The role of selectin-ligand binding in tumor metastasis. Activated endothelium secrets selectins, which mediate cancer cell rolling on the endothelium. Finally, the cancer cell migrates through the endothelium to other parts of the body.

adherent cells along vascular surfaces, which is essential for the recruitment of leukocytes to inflammation sites, platelets to injured tissues, hematopoietic stem cells to the bone marrow, and homing of naïve lymphocytes to secondary lymphoid organs (Lowe, 2003; Bhide and Colley, 2017). Selectin interactions are also involved in cancer progression and metastasis (Fig. 4). Cancer cell surfaces are enriched with glycans capped with SLX oligosaccharides which are correlated with increased cancer progression and poor prognosis (Fig. 5). Selectin-ligand interactions help cancer cells adhere to and extravasate through the endothelium, and inhibition of selectins reduces metastasis and tumor growth (Pinho and Reis, 2015). Altered sialylation patterns are seen following the induction of EMT, which allow cancer cells to break away from the primary tumors, invade into the extra-cellular matrix, and metastasize to distant organs to form secondary tumors (Sakuma, et al., 2012). Induction of EMT in colon cancer cells led to the upregulation of ST3GAL1, ST3GAL3 and ST3GAL4, which are responsible for the synthesis of SLX structures that serve as ligands for E-selectin (Sakuma, et al., 2012). As discussed above, sialylation was down-regulated during EMT and a set of sialylated proteins was dynamically regulated during EMT (Du, et al., 2015). Collectively, these evidences indicate that EMT was induced in cancer cells and resulted in the upregulation of SLX oligosaccharides, the ligands of selectin, promoting the invasion of cancer cells.

Siglecs, or sialic acid-binding immunoglobulin-type lectins, are another family of sialic acid-binding lectins that are involved in immune cell functions and diseases (O'Reilly and Paulson, 2009; Macauley, et al., 2014). Siglecs regulate the function of innate and adaptive immune cells, and help them discriminate between self and foreign antigens by recognizing species-specific sialylated glycans on the mammalian cell surface (Macauley, et al., 2014). Not surprisingly therefore, Siglecs play an important role in regulating cancer immune surveillance (Fuster and Esko, 2005) (Fig. 4). Siglec deficiencies have been reported in lymphomas and leukemia, and correlate with increased sialylation (Uckun, et al., 2010). Cancer cells are recognized as "non self" or "altered self" by innate lymphoid natural killer (NK) cells and innate immune responses are initiated (Jandus, et al., 2014), and the cancer cells need to evade the NK cells in order to proliferate, migrate and metastasize. The inhibitory receptors like Siglec-7 and Siglec-9 bind to sialic acid-containing ligands on the surface of a target cell and dampen NK cell activation. Two recent studies showed that high levels of Siglec-7 and Siglec-9 ligands on various cancer cells decreased their susceptibility to NK cell-mediated killing (Nicoll, et al., 2003; Hudak, et al., 2014).

\section{FUTURE DIRECTIONS}

In summary, our intent was to highlight exciting findings concerning the relationship between sialylation and cell fate decision during development, reprogramming and cancer progression. Since the discovery of the sialic acid 82 years ago, the roles of sialylation in the regulation of cell function are beginning to emerge. Research on the function of sialylation demonstrates that sialylated glycans are involved in multiple disciplines spanning immunology, neurobiology, ophthalmology, tumorigenicity, pluripotency, fertilization and development. It is increasingly apparent that the aberrant of sialylation lead to serious diseases, such as immune system abnormality, dry eyes, cancer, embryonic lethality and so on.

Despite the progress, the biological context of the functions of sialylation is still poorly understood. In particular, many enzymes and biological processes are involved in sialylation and a great effort should be put into the research of sialylation. Moreover, it is still difficult to identify which proteins are sialylated and to uncover the roles of sialylation. It is due to the imaginable diversity of sialylated glycans considering the number of monosaccharides, monosaccharides species as well as linkage modes that make it extremely difficult to confirm the glycoforms of a given sialylated proteins. Therefore, it is still lack of efficient technology to study sialylation.

A detailed understanding of the molecular mechanisms underlying the significance of sialylation on cell function during cell fate decision awaits further study, which will accelerate the pace of exploiting the knowledge for the development of agents with which to treat diseases and to enhance human health.

\section{ACKNOWLEDGEMENTS}

We are grateful to Xiuxiao Tang, Chuanhai Zhou and Han Lei for inspiring discussion and insightful comments. This research was funded by grants from National Key Research and Development 
Program 2016YFA (0101700) and 2017YFA0102800, the National Natural Science Foundation of China (Grant Nos. 31771639 and 81703086), Guangdong Innovative and Entrepreneurial Research Team Program 2016ZT06S029, the Fundamental Research Funds for the Central Universities (17ykzd04), and Thousand Youth Talents Plan to J. Ding and J. W., the National Natural Science Foundation of China (Grant No. 31771), and a project funded by China Postdoctoral Science Foundation (2017M622863).

\section{ABBREVIATIONS}

CA19-9, Sialyl Lewis A; CAM, cell adhesion molecules; CCR7, the C-C chemokine receptor type 7; CMP-Neu5Ac, cytidine 5'monophosphate $\mathrm{N}$-acetylneuraminic acid; CMP-Neu5Gc, cytidine 5'-monophosphate N-glycolylneuraminic acid; DHA, docosahexaenoic acid; DISC, death-inducing signaling complex; diSia, disialic acid; EBs, embryoid bodies; EMT, epithelial-mesenchymal transition; ESCs, embryonic stem cells; FADD, Fas-associated adaptor molecule; FasR, Fas receptor; FDA, Food and Drug Administration; Gal, galactose; GalNAc, N-acetylgalactosamine; GlcNAc, N-acetylglucosamine; IgG, immunoglobulin G; iPSC, induced pluripotent stem cell; Kdn, deaminoneuraminic acid; ManNAc, N-acetyl-Dmannosamine; ManNAc-6P, N-acyl-D-mannosamine 6-phosphate; MET, mesenchymal-epithelial transition; NCAM, neural cell adhesion molecule; NEU, Neuraminidases; Neu5Ac, $\mathrm{N}$-acetylneuraminic acid; Neu5Ac-9P, N-acylneuraminate 9-phosphate; Neu5Gc, N-glycolylneuraminic acid; NK, natural killer; NRP-2, neuropilin-2; OAT, sialate-O-acetyltransferase; oligoSia, oligosialic acid; polySia, polysialic acid; PSA, prostate-specific antigen; PTMs, post-translational modifications; SLX, Sialyl Lewis X; SNA, Sambucus nigra lectin; STn, Sialyl Tn; STs, sialyltransferases; SynCAM-1, synaptic cell adhesion molecule; TP, TSA/total protein; TSA, total sialic acid; UDP-GlcNAc, UDP-N-acetyl-glucosamine; UDP-GlcNAc 2-epimerase, UDP-N-acetylglucosamine-2-epimerase/ $\mathrm{N}$-acetylmannosamine kinase.

\section{COMPLIANCE WITH ETHICS GUIDELINES}

Fenjie Li and Junjun Ding declare no conflict of interest.

\section{OPEN ACCESS}

This article is distributed under the terms of the Creative Commons Attribution 4.0 International License (http://creativecommons.org/ licenses/by/4.0/), which permits unrestricted use, distribution, and reproduction in any medium, provided you give appropriate credit to the original author(s) and the source, provide a link to the Creative Commons license, and indicate if changes were made.

\section{REFERENCES}

Abeln M, Borst KM, Cajic S, Thiesler H, Kats E, Albers I, Kuhn M, Kaever V, Erdmann RB, Munster-Kuhnel A et al (2017) Sialylation is dispensable for early murine embryonic development in vitro. ChemBioChem 18(13):1305-1316

Angata T, Varki A (2002) Chemical diversity in the sialic acids and related alpha-keto acids: an evolutionary perspective. Chem Rev 102(2):439-469
Angata T, Kerr SC, Greaves DR, Varki NM, Crocker PR, Varki A (2002) Cloning and characterization of human Siglec-11. A recently evolved signaling molecule that can interact with SHP1 and SHP-2 and is expressed by tissue macrophages, including brain microglia. J Biol Chem 277(27):24466-24474

Badr HA, Alsadek DM, Darwish AA, Elsayed AI, Bekmanov BO, Khussainova EM, Zhang X, Cho WC, Djansugurova LB, Li CZ (2014) Lectin approaches for glycoproteomics in FDA-approved cancer biomarkers. Expert Rev Proteomics 11(2):227-236

Baldus SE, Zirbes TK, Monig SP, Engel S, Monaca E, Rafiqpoor K, Hanisch FG, Hanski C, Thiele J, Pichlmaier H et al (1998) Histopathological subtypes and prognosis of gastric cancer are correlated with the expression of mucin-associated sialylated antigens: Sialosyl-Lewis(a), Sialosyl-Lewis(x) and sialosyl-Tn. Tumour Biol 19(6):445-453

Ballehaninna UK, Chamberlain RS (2012) The clinical utility of serum CA 19-9 in the diagnosis, prognosis and management of pancreatic adenocarcinoma: An evidence based appraisal. J Gastrointest Oncol 3(2):105-119

Bhide GP, Colley KJ (2017) Sialylation of N-glycans: mechanism, cellular compartmentalization and function. Histochem Cell Biol 147(2):149-174

Bianconi E, Piovesan A, Facchin F, Beraudi A, Casadei R, Frabetti F, Vitale L, Pelleri MC, Tassani S, Piva F et al (2013) An estimation of the number of cells in the human body. Ann Human Biol 40 (6):463-471

Blix G (1936) Über die Kohlenhydratgruppen des Submaxillarismucins. Hoppe-Seyler's Zeitschrift für physiologische Chemie 240(1-2):43-54

Blix FG, Gottschalk A, Klenk E (1957) Proposed nomenclature in the field of neuraminic and sialic acids. Nature 179(4569):1088

Bonasio R, Tu S, Reinberg D (2010) Molecular signals of epigenetic states. Science 330(6004):612-616

Born GV, Palinski W (1985) Unusually high concentrations of sialic acids on the surface of vascular endothelia. $\mathrm{Br} \mathrm{J}$ Exp Pathol 66 (5):543-549

Cazet A, Julien S, Bobowski M, Krzewinski-Recchi MA, HarduinLepers A, Groux-Degroote S, Delannoy P (2010) Consequences of the expression of sialylated antigens in breast cancer. Carbohydr Res 345(10):1377-1383

Chen X, Varki A (2010) Advances in the biology and chemistry of sialic acids. ACS Chem Biol 5(2):163-176

Chu CS, Lo PW, Yeh YH, Hsu PH, Peng SH, Teng YC, Kang ML, Wong CH, Juan LJ (2014) O-GlcNAcylation regulates EZH2 protein stability and function. Proc Natl Acad Sci USA 111 (4):1355-1360

Close BE, Colley KJ (1998) In vivo autopolysialylation and localization of the polysialyltransferases PST and STX. J Biol Chem 273 (51):34586-34593

Coates SW, Gurney T Jr, Sommers LW, Yeh M, Hirschberg CB (1980) Subcellular localization of sugar nucleotide synthetases. J Biol Chem 255(19):9225-9229

Comb DG, Roseman S (1958) Enzymic synthesis of N-acetyl-Dmannosamine. Biochim Biophys Acta 29(3):653-654

Corfield AP (2015) Mucins: a biologically relevant glycan barrier in mucosal protection. Biochim Biophys Acta 1850(1):236-252 
Corfield AP, Myerscough N, Warren BF, Durdey P, Paraskeva C, Schauer R (1999) Reduction of sialic acid O-acetylation in human colonic mucins in the adenoma-carcinoma sequence. Glycoconj J 16(6):307-317

Cui HX, Wang H, Wang Y, Song J, Tian H, Xia C, Shen Y (2016) ST3Gal III modulates breast cancer cell adhesion and invasion by altering the expression of invasion-related molecules. Oncol Rep 36(6):3317-3324

Dalziel M, Whitehouse C, McFarlane I, Brockhausen I, Gschmeissner S, Schwientek T, Clausen H, Burchell JM, Taylor-Papadimitriou J (2001) The relative activities of the C2GnT1 and ST3Gal-I glycosyltransferases determine O-glycan structure and expression of a tumor-associated epitope on MUC1. J Biol Chem 276 (14):11007-11015

Dao TL, Ip C, Patel J (1980) Serum sialyltransferase and 5'nucleotidase as reliable biomarkers in women with breast cancer. J Natl Cancer Inst 65(3):529-534

Deng LQ, Chen X, Varki A (2013) Exploration of sialic acid diversity and biology using sialoglycan microarrays. Biopolymers 99 (10):650-665

Dickson JJ, Messer M (1978) Intestinal neuraminidase activity of suckling rats and other mammals. Relationship to the sialic acid content of milk. Biochem J 170(2):407-413

Du J, Meledeo MA, Wang Z, Khanna HS, Paruchuri VD, Yarema KJ (2009) Metabolic glycoengineering: sialic acid and beyond. Glycobiology 19(12):1382-1401

Du J, Hong S, Dong L, Cheng B, Lin L, Zhao B, Chen YG, Chen X (2015) Dynamic sialylation in transforming growth factor-beta (TGF-beta)-induced epithelial to mesenchymal transition. J Biol Chem 290(19):12000-12013

Duraker N, Hot S, Polat Y, Hobek A, Gencler N, Urhan N (2007) CEA, CA 19-9, and CA 125 in the differential diagnosis of benign and malignant pancreatic diseases with or without jaundice. J Surg Oncol 95(2):142-147

Eckhardt M, Gerardy-Schahn R (1998) Genomic organization of the murine polysialyltransferase gene ST8SialV (PST-1). Glycobiology 8(12):1165-1172

Evans MJ, Kaufman MH (1981) Establishment in culture of pluripotential cells from mouse embryos. Nature 292(5819):154-156

Eylar EH, Madoff MA, Brody OV, Oncley JL (1962) The contribution of sialic acid to the surface charge of the erythrocyte. J Biol Chem 237:1992-2000

Fleming SC, Smith S, Knowles D, Skillen A, Self CH (1998) Increased sialylation of oligosaccharides on IgG paraproteins-a potential new tumour marker in multiple myeloma. J Clin Pathol 51(11):825-830

Fuster MM, Esko JD (2005) The sweet and sour of cancer: Glycans as novel therapeutic targets. Nat Rev Cancer 5(7):526-542

Gal B, Ruano MJ, Puente R, Garcia-Pardo LA, Rueda R, Gil A, Hueso $P$ (1997) Developmental changes in UDP-N-acetylglucosamine 2-epimerase activity of rat and guinea-pig liver. Comp Biochem Physiol B: Biochem Mol Biol 118(1):13-15

Gerardy-Schahn R, Delannoy P, von Itzstein M (2015) SialoGlyco chemistry and biology II tools and techniques to identify and capture sialoglycans preface. Sialoglyco Chemistry and Biology li 367:V-Vii
Ghosh S, Roseman S (1961) Enzymatic phosphorylation of $\mathrm{N}$-acetyl-D-mannosamine. Proc Natl Acad Sci USA 47:955-958

Hakomori S (1985) Aberrant glycosylation in cancer cell membranes as focused on glycolipids: overview and perspectives. Cancer Res 45(6):2405-2414

Hamamoto T, Kawasaki M, Kurosawa N, Nakaoka T, Lee YC, Tsuji S (1993) Two step single primer mediated polymerase chain reaction. Application to cloning of putative mouse, beta-galactoside alpha 2,6-sialyltransferase cDNA. Bioorg Med Chem 1 (2):141-145

Hanover JA (2001) Glycan-dependent signaling: O-linked N-acetylglucosamine. FASEB J 15(11):1865-1876

Hasehira K, Tateno H, Onuma Y, Ito Y, Asashima M, Hirabayashi J (2012) Structural and quantitative evidence for dynamic glycome shift on production of induced pluripotent stem cells. Mol Cell Proteomics 11(12):1913-1923

Hata K, Tochigi T, Sato I, Kawamura S, Shiozaki K, Wada T, Takahashi K, Moriya S, Yamaguchi K, Hosono M et al (2015) Increased sialidase activity in serum of cancer patients: Identification of sialidase and inhibitor activities in human serum. Cancer Sci 106(4):383-389

Hatano K, Miyamoto Y, Mori M, Nimura K, Nakai Y, Nonomura N, Kaneda $Y$ (2012) Androgen-regulated transcriptional control of sialyltransferases in prostate cancer cells. PLoS ONE 7(2): e31234

Henderson M, Kessel D (1977) Alterations in plasma sialyltransferase levels in patients with neoplastic disease. Cancer 39 (3):1129-1134

Hudak JE, Canham SM, Bertozzi CR (2014) Glycocalyx engineering reveals a Siglec-based mechanism for NK cell immunoevasion. Nat Chem Biol 10(1):69-75

Ikehara Y, Shimizu N, Kono M, Nishihara S, Nakanishi H, Kitamura T, Narimatsu H, Tsuji S, Tatematsu M (1999) A novel glycosyltransferase with a polyglutamine repeat; a new candidate for GD1alpha synthase (ST6GalNAc V)(1). FEBS Lett 463(1-2):9296

James WM, Agnew WS (1987) Multiple oligosaccharide chains in the voltage-sensitive $\mathrm{Na}$ channel from electrophorus electricus: evidence for alpha-2,8-linked polysialic acid. Biochem Biophys Res Commun 148(2):817-826

Jandus C, Boligan KF, Chijioke O, Liu H, Dahlhaus M, Demoulins T, Schneider C, Wehrli M, Hunger RE, Baerlocher GM et al (2014) Interactions between Siglec-7/9 receptors and ligands influence NK cell-dependent tumor immunosurveillance. J Clin Investig 124 (4):1810-1820

Jiang C, Liu S, He W, Zhang B, Xia L (2017) The prognostic and predictive value of carbohydrate antigen 19-9 in metastatic colorectal cancer patients with first line bevacizumab containing chemotherapy. J Cancer 8(8):1410-1416

Jones RB, Dorsett KA, Hjelmeland AB, Bellis SL (2018) The ST6Gal-I sialyltransferase protects tumor cells against hypoxia by enhancing HIF-1a signaling. J Biol Chem 293(15):jbc-RA117

Jourdian GW, Swanson AL, Watson D, Roseman S (1964) Isolation of sialic acid 9-phosphatase from human erythrocytes. J Biol Chem 239:PC2714-6

Kakugawa Y, Wada T, Yamaguchi K, Yamanami H, Ouchi K, Sato I, Miyagi T (2002) Up-regulation of plasma membrane-associated 
ganglioside sialidase (Neu3) in human colon cancer and its involvement in apoptosis suppression. Proc Natl Acad Sci USA 99(16):10718-10723

Kannagi R (2007) Carbohydrate antigen sialyl Lewis a-its pathophysiological significance and induction mechanism in cancer progression. Chang Gung Med J 30(3):189-209

Kashef J, Franz CM (2015) Quantitative methods for analyzing cellcell adhesion in development. Dev Biol 401(1):165-174

Kiermaier E, Moussion C, Veldkamp CT, Gerardy-Schahn R, de Vries I, Williams LG, Chaffee GR, Phillips AJ, Freiberger F, Imre $R$ et al (2016) Polysialylation controls dendritic cell trafficking by regulating chemokine recognition. Science 351(6269):186-190

Klenk E (1941) Neuraminsäure, das Spaltprodukt eines neuen Gehirnlipoids. Hoppe-Seyler's Zeitschrift für physiologische Chemie 268(1-2):50-58

Kochlamazashvili G, Senkov O, Grebenyuk S, Robinson C, Xiao MF, Stummeyer K, Gerardy-Schahn R, Engel AK, Feig L, Semyanov $A$ et al (2010) Neural cell adhesion molecule-associated polysialic acid regulates synaptic plasticity and learning by restraining the signaling through GluN2B-containing NMDA receptors. J Neurosci 30(11):4171-4183

Kodar K, Stadlmann J, Klaamas K, Sergeyev B, Kurtenkov O (2012) Immunoglobulin G Fc N-glycan profiling in patients with gastric cancer by LC-ESI-MS: relation to tumor progression and survival. Glycoconj J 29(1):57-66

Kono M, Takashima S, Liu H, Inoue M, Kojima N, Lee YC, Hamamoto T, Tsuji S (1998) Molecular cloning and functional expression of a fifth-type alpha 2,3-sialyltransferase (mST3Gal V: GM3 synthase). Biochem Biophys Res Commun 253(1):170-175

Krzewinski-Recchi MA, Julien S, Juliant S, Teintenier-Lelievre M, Samyn-Petit B, Montiel MD, Mir AM, Cerutti M, Harduin-Lepers A, Delannoy $P$ (2003) Identification and functional expression of a second human beta-galactoside alpha 2,6-sialyltransferase, ST6Gal II. Eur J Biochem 270(5):950-961

Kurosawa N, Inoue M, Yoshida Y, Tsuji S (1996) Molecular cloning and genomic analysis of mouse Galbeta 1, 3GalNAc-specific GalNAc alpha2,6-sialyltransferase. J Biol Chem 271(25):1510915116

Lau KS, Partridge EA, Grigorian A, Silvescu Cl, Reinhold VN, Demetriou M, Dennis JW (2007) Complex N-glycan number and degree of branching cooperate to regulate cell proliferation and differentiation. Cell 129(1):123-134

Le Marer N, Laudet V, Svensson EC, Cazlaris H, Van Hille B, Lagrou C, Stehelin D, Montreuil J, Verbert A, Delannoy P (1992) The $\mathrm{C}$-Ha-ras oncogene induces increased expression of beta-galactoside alpha-2, 6-sialyltransferase in rat fibroblast (FR3T3) cells. Glycobiology 2(1):49-56

Lee YC, Kojima N, Wada E, Kurosawa N, Nakaoka T, Hamamoto T, Tsuji S (1994) Cloning and expression of cDNA for a new type of Gal beta 1,3GalNAc alpha 2,3-sialyltransferase. J Biol Chem 269 (13):10028-10033

Li RH, Liang JL, Ni S, Zhou T, Qing XB, Li HP, He WZ, Chen JK, Li F, Zhuang QA et al (2010) A mesenchymal-to-epithelial transition initiates and is required for the nuclear reprogramming of mouse fibroblasts. Cell Stem Cell 7(1):51-63

Liang Y, Xu P, Zou Q, Luo H, Yu W (2018) An epigenetic perspective on tumorigenesis: loss of cell identity, enhancer switching, and
NamiRNA network. Semin Cancer Biol. https://doi.org/10.1016/j. semcancer.2018.09.004

Liu XP, Sun H, Qi J, Wang LL, He SW, Liu J, Feng CQ, Chen CL, Li W, Guo YQ et al (2013) Sequential introduction of reprogramming factors reveals a time-sensitive requirement for individual factors and a sequential EMT-MET mechanism for optimal reprogramming. Nat Cell Biol 15(7):829-+

Lowe JB (2003) Glycan-dependent leukocyte adhesion and recruitment in inflammation. Curr Opin Cell Biol 15(5):531-538

Ludwig JA, Weinstein JN (2005) Biomarkers in cancer staging, prognosis and treatment selection. Nat Rev Cancer 5(11):845856

Macauley MS, Crocker PR, Paulson JC (2014) Siglec-mediated regulation of immune cell function in disease. Nat Rev Immunol 14(10):653-666

Macbeth RALBJG (1962) Plasma glycoproteins in various disease states including carcinoma. Cancer Res 22(10):1170-1176

Margolis RK, Margolis RU (1983) Distribution and characteristics of polysialosyl oligosaccharides in nervous tissue glycoproteins. Biochem Biophys Res Commun 116(3):889-894

Melo-Braga MN, Schulz M, Liu QY, Swistowski A, Palmisano G, Engholm-Keller K, Jakobsen L, Zeng XM, Larsen MR (2014) Comprehensive quantitative comparison of the membrane proteome, phosphoproteome, and sialiome of human embryonic and neural stem cells. Mol Cell Proteomics 13(1):311-328

Mincarelli L, Lister A, Lipscombe J, Macaulay IC (2018) Defining cell identity with single-cell omics. Proteomics 18(18):e1700312

Miyagi T, Takahashi K, Hata K, Shiozaki K, Yamaguchi K (2012) Sialidase significance for cancer progression. Glycoconj J 29(89):567-577

Moris N, Pina C, Arias AM (2016) Transition states and cell fate decisions in epigenetic landscapes. Nat Rev Genet 17(11):693703

Moyer VA, Force USPST (2012) Screening for prostate cancer: U.S. Preventive Services Task Force recommendation statement. Ann Intern Med 157(2):120-134

Muhlenhoff M, Rollenhagen M, Werneburg S, Gerardy-Schahn R, Hildebrandt $H$ (2013) Polysialic acid: versatile modification of NCAM, SynCAM 1 and neuropilin-2. Neurochem Res 38 (6):1134-1143

Nakagoe T, Sawai T, Tsuji T, Jibiki M, Nanashima A, Yamaguchi $H$, Kurosaki N, Yasutake T, Ayabe $\mathrm{H}$ (2001) Circulating sialyl Lewis (x), sialyl Lewis(a), and sialyl Tn antigens in colorectal cancer patients: multivariate analysis of predictive factors for serum antigen levels. J Gastroenterol 36(3):166-172

Nicoll G, Avril T, Lock K, Furukawa K, Bovin N, Crocker PR (2003) Ganglioside GD3 expression on target cells can modulate NK cell cytotoxicity via siglec-7-dependent and -independent mechanisms. Eur J Immunol 33(6):1642-1648

Nomura H, Tamada Y, Miyagi T, Suzuki A, Taira M, Suzuki N, Susumu N, Irimura T, Aoki D (2006) Expression of NEU3 (plasma membrane-associated sialidase) in clear cell adenocarcinoma of the ovary: its relationship with T factor of pTNM classification. Oncol Res 16(6):289-297

O'Reilly MK, Paulson JC (2009) Siglecs as targets for therapy in immune-cell-mediated disease. Trends Pharmacol Sci 30 (5):240-248 
Okajima T, Fukumoto S, Miyazaki H, Ishida H, Kiso M, Furukawa K, Urano T, Furukawa K (1999) Molecular cloning of a novel alpha 2,3-sialyltransferase (ST3Gal VI) that sialylates type II lactosamine structures on glycoproteins and glycolipids. J Biol Chem 274(17):11479-11486

Okajima T, Chen HH, Ito H, Kiso M, Tai T, Furukawa K, Urano T, Furukawa K (2000) Molecular cloning and expression of mouse GD1alpha/GT1aalpha/GQ1balpha synthase (ST6GalNAc VI) gene. J Biol Chem 275(10):6717-6723

Parekh RB, Dwek RA, Sutton BJ, Fernandes DL, Leung A, Stanworth D, Rademacher TW, Mizuochi T, Taniguchi T, Matsuta $\mathrm{K}$ et al (1985) Association of rheumatoid arthritis and primary osteoarthritis with changes in the glycosylation pattern of total serum IgG. Nature 316(6027):452-457

Pihikova D, Kasak P, Kubanikova P, Sokol R, Tkac J (2016) Aberrant sialylation of a prostate-specific antigen: Electrochemical labelfree glycoprofiling in prostate cancer serum samples. Anal Chim Acta 934:72-79

Pinho SS, Reis CA (2015) Glycosylation in cancer: mechanisms and clinical implications. Nat Rev Cancer 15(9):540-555

Pucic M, Knezevic A, Vidic J, Adamczyk B, Novokmet M, Polasek O, Gornik O, Supraha-Goreta S, Wormald MR, Redzic I et al (2011) High throughput isolation and glycosylation analysis of IgGvariability and heritability of the IgG glycome in three isolated human populations. Mol Cell Proteomics 10(10):M111 010090

Raval GN, Patel DD, Parekh LJ, Patel JB, Shah MH, Patel PS (2003) Evaluation of serum sialic acid, sialyltransferase and sialoproteins in oral cavity cancer. Oral Dis 9(3):119-128

Roseman S, Jourdian GW, Watson D, Rood R (1961) Enzymatic synthesis of sialic acid 9-phosphates. Proc Natl Acad Sci USA 47:958-961

Saito S, Onuma Y, Ito Y, Tateno H, Toyoda M, Hidenori A, Nishino K, Chikazawa E, Fukawatase Y, Miyagawa $Y$ et al (2011) Possible linkages between the inner and outer cellular states of human induced pluripotent stem cells. BMC Syst Biol 5(Suppl 1):S17

Sakuma K, Aoki M, Kannagi R (2012) Transcription factors c-Myc and CDX2 mediate E-selectin ligand expression in colon cancer cells undergoing EGF/bFGF-induced epithelial-mesenchymal transition. Proc Natl Acad Sci USA 109(20):7776-7781

Saldova R, Wormald MR, Dwek RA, Rudd PM (2008) Glycosylation changes on serum glycoproteins in ovarian cancer may contribute to disease pathogenesis. Dis Markers 25(4-5):219-232

Santos-Silva F, Fonseca A, Caffrey T, Carvalho F, Mesquita P, Reis C, Almeida R, David L, Hollingsworth MA (2005) ThomsenFriedenreich antigen expression in gastric carcinomas is associated with MUC1 mucin VNTR polymorphism. Glycobiology 15 (5):511-517

Sasaki K, Watanabe E, Kawashima K, Sekine S, Dohi T, Oshima M, Hanai N, Nishi T, Hasegawa M (1993) Expression cloning of a novel Gal beta (1-3/1-4) GIcNAc alpha 2,3-sialyltransferase using lectin resistance selection. J Biol Chem 268(30):22782-22787

Sato C, Kitajima K (2013) Disialic, oligosialic and polysialic acids: distribution, functions and related disease. J Biochem 154 (2):115-136

Sawhney H, Kumar CA (2011) Correlation of serum biomarkers (TSA \& LSA) and epithelial dysplasia in early diagnosis of oral precancer and oral cancer. Cancer Biomark 10(1):43-49
Schroeder FH, Hugosson J, Roobol MJ, Tammela TLJ, Ciatto S, Nelen V, Kwiatkowski M, Lujan M, Lilja H, Zappa M et al (2009) Screening and Prostate-Cancer Mortality in a Randomized European Study. N Engl J Med 360(13):1320-1328

Schultz MJ, Holdbrooks AT, Chakraborty A, Grizzle WE, Landen CN, Buchsbaum DJ, Conner MG, Arend RC, Yoon KJ, Klug CA et al (2016) The tumor-associated glycosyltransferase ST6Gal-I regulates stem cell transcription factors and confers a cancer stem cell phenotype. Cancer Res 76(13):3978-3988

Schwarzkopf M, Knobeloch KP, Rohde E, Hinderlich S, Wiechens N, Lucka L, Horak I, Reutter W, Horstkorte R (2002) Sialylation is essential for early development in mice. Proc Natl Acad Sci USA 99(8):5267-5270

Seales EC, Jurado GA, Singhal A, Bellis SL (2003) Ras oncogene directs expression of a differentially sialylated, functionally altered beta1 integrin. Oncogene 22(46):7137-7145

Seales EC, Shaikh FM, Woodard-Grice AV, Aggarwal P, McBrayer AC, Hennessy KM, Bellis SL (2005) A protein kinase C/Ras/ERK signaling pathway activates myeloid fibronectin receptors by altering beta1 integrin sialylation. J Biol Chem 280(45):3761037615

Shah MH, Telang SD, Shah PM, Patel PS (2008) Tissue and serum alpha 2-3- and alpha 2-6-linkage specific sialylation changes in oral carcinogenesis. Glycoconj J 25(3):279-290

Stojkovic Lalosevic M, Stankovic S, Stojkovic M, Markovic V, Dimitrijevic I, Lalosevic J, Petrovic J, Brankovic M, Pavlovic Markovic A, Krivokapic Z (2017) Can preoperative CEA and CA19-9 serum concentrations suggest metastatic disease in colorectal cancer patients? Hell J Nucl Med 20(1):41-45

Suzuki O, Abe M, Hashimoto $Y$ (2015) Sialylation by betagalactoside alpha-2,6-sialyltransferase and $\mathrm{N}$-glycans regulate cell adhesion and invasion in human anaplastic large cell lymphoma. Int J Oncol 46(3):973-980

Svennerholm L, Bostrom K, Fredman P, Mansson JE, Rosengren B, Rynmark BM (1989) Human brain gangliosides: developmental changes from early fetal stage to advanced age. Biochim Biophys Acta 1005(2):109-117

Swindall AF, Bellis SL (2011) Sialylation of the Fas death receptor by ST6Gal-I provides protection against Fas-mediated apoptosis in colon carcinoma cells. J Biol Chem 286(26):22982-22990

Tajiri M, Ohyama C, Wada Y (2008) Oligosaccharide profiles of the prostate specific antigen in free and complexed forms from the prostate cancer patient serum and in seminal plasma: a glycopeptide approach. Glycobiology 18(1):2-8

Takahashi K, Yamanaka S (2006) Induction of pluripotent stem cells from mouse embryonic and adult fibroblast cultures by defined factors. Cell 126(4):663-676

Takashima S, Tachida Y, Nakagawa T, Hamamoto T, Tsuji S (1999) Quantitative analysis of expression of mouse sialyltransferase genes by competitive PCR. Biochem Biophys Res Commun 260 (1):23-27

Takashima S, Ishida HK, Inazu T, Ando T, Ishida H, Kiso M, Tsuji S, Tsujimoto M (2002) Molecular cloning and expression of a sixth type of alpha 2,8-sialyltransferase (ST8Sia VI) that sialylates O-glycans. J Biol Chem 277(27):24030-24038

Theodoratou E, Thaci K, Agakov F, Timofeeva MN, Stambuk J, Pucic-Bakovic M, Vuckovic F, Orchard P, Agakova A, Din FV et al 
(2016) Glycosylation of plasma IgG in colorectal cancer prognosis. Sci Rep 6:28098

Uckun FM, Goodman P, Ma H, Dibirdik I, Qazi S (2010) CD22 EXON 12 deletion as a pathogenic mechanism of human B-precursor leukemia. Proc Natl Acad Sci USA 107(39):16852-16857

van Karnebeek CDM, Bonafe L, Wen XY, Tarailo-Graovac M, Balzano S, Royer-Bertrand B, Ashikov A, Garavelli L, Mammi I, Turolla $L$ et al (2017) NANS-mediated synthesis of sialic acid is required for brain and skeletal development (vol 48, pg 777, 2016). Nat Genet 49(6):969

Varki A (2008) Sialic acids in human health and disease. Trends Mol Med 14(8):351-360

Vuckovic F, Theodoratou E, Thaci K, Timofeeva M, Vojta A, Stambuk J, Pucic-Bakovic M, Rudd PM, Derek L, Servis D et al (2016) IgG glycome in colorectal cancer. Clin Cancer Res 22(12):3078-3086

Wang B (2009) Sialic acid is an essential nutrient for brain development and cognition. Annu Rev Nutr 29:177-222

Wang B (2012) Molecular mechanism underlying sialic acid as an essential nutrient for brain development and cognition. Advances in Nutrition 3(3):465s-472s

Wang B, Brand-Miller J, McVeagh P, Petocz P (2001) Concentration and distribution of sialic acid in human milk and infant formulas. Am J Clin Nutr 74(4):510-515

Wang B, McVeagh P, Petocz P, Brand-Miller J (2003) Brain ganglioside and glycoprotein sialic acid in breastfed compared with formula-fed infants. Am J Clin Nutr 78(5):1024-1029

Wang YC, Peterson SE, Loring JF (2014) Protein post-translational modifications and regulation of pluripotency in human stem cells. Cell Res 24(2):143-160

Wang YC, Stein JW, Lynch CL, Tran HT, Lee CY, Coleman R, Hatch A, Antontsev VG, Chy HS, O'Brien CM et al (2015) Glycosyltransferase ST6GAL1 contributes to the regulation of pluripotency in human pluripotent stem cells. Sci Rep 5:13317

Weber KS, Alon R, Klickstein LB (2004) Sialylation of ICAM-2 on platelets impairs adhesion of leukocytes via LFA-1 and DC-SIGN. Inflammation 28(4):177-188

Werneburg S, Buettner FF, Erben L, Mathews M, Neumann H, Muhlenhoff M, Hildebrandt H (2016) Polysialylation and lipopolysaccharide-induced shedding of E-selectin ligand-1 and neuropilin-2 by microglia and THP-1 macrophages. Glia 64 (8):1314-1330

Yabe U, Sato C, Matsuda T, Kitajima K (2003) Polysialic acid in human milk-CD36 is a new member of mammalian polysialic acid-containing glycoprotein. J Biol Chem 278(16):13875-13880

Yang X, Qian K (2017) Protein O-GlcNAcylation: emerging mechanisms and functions. Nat Rev Mol Cell Biol 18(7):452-465

Yang PMD, Rutishauser U (1994) Role of charge and hydration in effects of polysialic acid on molecular interactions on and between cell membranes. J Biol Chem 269(37):23039-23044

Yoneyama T, Ohyama C, Hatakeyama S, Narita S, Habuchi T, Koie T, Mori K, Hidari KIPJ, Yamaguchi M, Suzuki T et al (2014) Measurement of aberrant glycosylation of prostate specific antigen can improve specificity in early detection of prostate cancer. Biochem Biophys Res Commun 448(4):390-396

Yoshida Y, Kojima N, Tsuji S (1995) Molecular cloning and characterization of a third type of $\mathrm{N}$-glycan alpha 2,8-sialyltransferase from mouse lung. J Biochem 118(3):658-664

Zhang D, Chen BC, Wang YM, Xia P, He CY, Liu YJ, Zhang RQ, Zhang M, Li ZL (2016) Disease-specific IgG FC N-glycosylation as personalized biomarkers to differentiate gastric cancer from benign gastric diseases. Sci Rep 6:25957

Zhao J, Simeone DM, Heidt D, Anderson MA, Lubman DM (2006) Comparative serum glycoproteomics using lectin selected sialic acid glycoproteins with mass spectrometric analysis: Application to pancreatic cancer serum. J Proteome Res 5(7):1792-1802

Zhao ZA, Yu Y, Ma HX, Wang XX, Lu X, Zhai Y, Zhang X, Wang H, Li $L$ (2015) The roles of ERAS during cell lineage specification of mouse early embryonic development. Open Biol 5(8):150092

Zhao T, Fu Y, Zhu J, Liu Y, Zhang Q, Yi Z, Chen S, Jiao Z, Xu X, Xu J et al (2018) Single-cell RNA-Seq reveals dynamic early embryonic-like programs during chemical reprogramming. Cell Stem Cell 23(1):31-45 e7

Zhou Q, Melton DA (2008) Extreme makeover: converting one cell into another. Cell Stem Cell 3(4):382-388 